\section{Simultaneous Isolation of Tonoplast and Plasmalemma from Citrus Juice Cells: Combination of Sucrose Gradient and Two Phase Partitioning}

Ed Etxeberria and Pedro Gonzalez

University of Florida, Institute of Food and Agricultural Sciences, Citrus Research and Education Center, 700 Experiment Station Road, Lake Alfred, FL 33850-2229

Additional index words. sucrose uptake, sink strength, storage tissue

\begin{abstract}
By combining the principles of density gradient separation and two phase partitioning, we devised a system to obtain highly pure plasmalemma and tonoplast vesicles from citrus (Citrus limettioides Tan.) juice cells. Both tonoplast and plasmalemma fractions were virtually free from golgi, endoplasmic reticulum and mitochondria contamination. Plasmalemma and tonoplast samples were also clean from each other cross-contaminants. Immediately after isolation, $72 \%$ of the plasmalemma and $82 \%$ of the tonoplast vesicles were oriented rightside-out according to enzyme marker activities. After freezing and thawing, however, plasmalemma vesicles re-oriented evenly but orientation of tonoplast vesicles remained unchanged. Differential changes in marker activities before and after freezing and thawing indicated that the low levels of plasmalemma contamination within the tonoplast fractions were due to the presence of a separate population of plasmalemma vesicles and not to the existence of hybrid vesicles. The method described in this communication allows for future studies on photoassimilate accumulation in cells of important horticultural storage organs.
\end{abstract}

Transport of photoassimilates to the storage cells of developing terminal organs, such as fruits and tubers, is an important sink activity that can take several routes depending on the developmental stage (Patrick, 1997). Assimilates can move either symplastically through the plasmodesmata, or apoplastically through the cell wall. In the apoplastic route, solutes are presumably transferred from the apoplast and eventually into the vacuole through a series of channels, pumps and transporters located at both the plasmalemma and tonoplast. Various of these transporters have been well characterized, and include ions channels, pumps, and secondary active carbohydrate transporters (Barkla and Pantoja, 1996; Maathuis and Sanders, 1999; Martinoia et al., 2000). However, most studies on photoassimilate transport have been conducted with only one membrane system (plasmalemma or tonoplast), a situation that prevents a complete assessment and understanding of the overall processes of solute accumulation into the cell, and hence, plant productivity. In many cells where sucrose is believed to accumulate in the vacuole against a concentration gradient, active transport mechanisms have not often been found. For example, in sweet lime (Citrus limettioides Tan.), an active transport system for sucrose uptake at the tonoplast was not detected (Echeverria et al., 1997) suggesting that the sucrose accumulating

Received for publication 1 July 2002. Accepted for publication 9Apr. 2003. This research was supported by the Rural Development Administration of the Republic of Korea and by the Florida Agricultural Experiment Station, and approved for publication as Journal Series No. R-08930. step resides at the plasmalemma. A similar situation was reported for tomato (Lycopersicum esculentum Mill.) pericarp (Milner et al., 1995), where the lack of active sucrose transport at the tonoplast implicated the plasmalemma as the accumulating barrier. This conjecture was later confirmed by the use of protoplasts (Ruan et al., 1997). A most intriguing example is that of sugarcane (Saccharum officinarum ssp.), which stores sucrose at concentrations of over $500 \mathrm{~mm}$, but no active sucrose carrier has been found at the tonoplast (Presser and Komor, 1991).

In instances where active photoassimilate transport systems have been identified at the tonoplast, no corresponding information has been presented concerning transport across the plasmalemma. In apple fruit (Malus pumila Mill.), transport of sorbitol into the vacuole appears to be ATP-dependent (Yamaki, 1987), but no detail on how sorbitol enters the cell was provided. Asimilar situation is encountered for sucrose transport into red beet (Beta vulgaris L.) hypocotyl (Getz, 1991) and stachyose accumulation in tubers of Stachys sieboldii Miq. (Keller, 1992).

A primary reason for the lack of complementary data on plasmalemma and tonoplast transport is the inadequacy of existing methods in generating, from the same sample, useful membranes fractions for dual analyses of both tonoplast and plasmalemma. Our current efforts to understand photoassimilates uptake into citrus juice cells prompted us to design a system for the isolation of tonoplast and plasmalemma by combining existing principles of density gradient and two phase partition. Previous attempts to separate tonoplast and plasmalemma using sucrose density gradient were futile, since the plasmalemma fraction always remained heavily contaminated by mitochondria, endoplastic reticulum and golgi (unpublished data).

\section{Materials and Methods}

Palestine sweet limes (Citrus limettioides Tan.) were collected from groves located at the Citrus Research and Education Center in Lake Alfred, Fla. A total of $150 \mathrm{~mL}$ of juice from five different fruits were combined with $150 \mathrm{~mL}$ of a buffered solution containing 0.5 м 3-[NMorpholino]propane-sulfonic acid (MOPS)/ $\mathrm{KOH}$ (pH 8.0), 1.5\% polyvinyl-pyrrolidonee40 (PVP-40), 2 mм dithiothrietol (DTT), 3.5 mm ethylenediaminetetra-acetic acid (EDTA), $250 \mathrm{~mm}$ sucrose, $0.1 \%$ bovine serum albumin (BSA), and 1 mu phenylmethanesulfonyl fluoride (PMSF). The homogenate was squeezed through two layers of cheesecloth and centrifuged at $10,000 g_{\mathrm{n}}$ for $10 \mathrm{~min}$. The supernatant was centrifuged at $65,000 g_{\mathrm{n}}$ for $30 \mathrm{~min}$, and the pellet $\left(\mathrm{P}_{1}\right)$ was set aside for plasmalemma purification. The remaining supernatant was centrifuged once again at $100,000 g_{n}$ for an additional $60 \mathrm{~min}$ and the pellet $\left(\mathrm{P}_{2}\right)$ used for tonoplast purification.

\section{Results and Discussion}

The initial centrifugation step of the buffered juice extract eliminated debris and virtually all mitochondria contamination as shown in Table 1. For further plasmalemma isolation, $\mathrm{P}_{1}$ was re-suspended in $10 \mathrm{~mL}$ of $330 \mathrm{~mm}$ sucrose, $3 \mathrm{~mm} \mathrm{KCl}$ and $4 \mathrm{~mm} \mathrm{KHPO}_{4}$ (pH 7.8). The suspension was combined with $27.0 \mathrm{~g}$ "phase mixture" at 1:3 ratio of dextranpolyethylene glycol as described by Larsson et al. (1987). Plasmalemma isolation by two phase partitioning, which separates membranes according to surface properties, was carried out following the method of Larsson et al. (1987) except that the membrane sample in the upper PEG layer was ultimately re-suspended in $500 \mu \mathrm{L}$ of $10 \mathrm{~mm}$ Bis-tris propane (BTP)/Mes (pH 7.5), 2 mm DTT and 250 mm sorbitol. After resuspension, a highly pure plasmalemma fraction was obtained (Table 1). The plasmalemma fraction was virtually free of tonoplast, mitochondria and ER, and contained only $13 \%$ contamination with dictyosome (Table 1). Degree of plasmalemma purity was calculated using NADH oxidase as plasmalemma marker given that citrus juice cells contain a vanadate sensitive V-ATPase (Brune et al., 2002; Müller et al., 1996, 1997), which would have underestimated purity if if P-ATPase were used as marker instead.

To further purify the tonoplast fraction, $\mathrm{P}_{2}$ was re-suspended in $10 \mathrm{~mL}$ of a solution containing $50 \mathrm{~mm} \mathrm{BTP/Mes} \mathrm{(pH} \mathrm{7.6),} 100 \mathrm{~mm} \mathrm{KCl}$, $150 \mathrm{~mm}$ sucrose, and $2 \mathrm{~mm}$ DTT. The suspension was layered on $25.0 \mathrm{~mL}$ sucrose cushion of $17 \%$ sucrose in $10 \mathrm{mM} \mathrm{BTP/Mes} \mathrm{(pH} \mathrm{7.6),}$ $2 \mathrm{~mm}$ DTT, $10 \%$ glycerol and $20 \mathrm{~mm} \mathrm{KCl}$. The tubes were centrifuged at $100,000 g_{n}$ for $1 \mathrm{~h}$. After centrifugation, the membrane interface on top of the cushion was collected, diluted 
Table 1. Activities of marker enzymes in membrane samples isolated as described above. The data are the average of three replicates. Standard of error (SE) did not exceed $\pm 9 \%$. Enzymes were assayed as follow: ATPase (Marsh et al., 2001). Cytochrome-c oxidase and reductase (Larsson et al., 1987). NADH-oxidase (Hadzi-Taskovic and Vuletic, 1998), UDPase (Joyce et al., 1988).

\begin{tabular}{|c|c|c|c|c|c|c|c|}
\hline & \multirow[b]{2}{*}{$\begin{array}{l}\text { Microsomal } \\
\text { pellet }^{2, y}\end{array}$} & \multicolumn{3}{|c|}{ Tonoplast fraction } & \multicolumn{3}{|c|}{ Plasmalemma fraction } \\
\hline & & Total & $\begin{array}{c}\text { Recovered } \\
(\%)\end{array}$ & $\begin{array}{c}\text { Contamination } \\
(\%)\end{array}$ & Total $^{\mathrm{y}}$ & $\begin{array}{c}\text { Recovered } \\
(\%)\end{array}$ & $\begin{array}{c}\text { Contamination } \\
(\%)\end{array}$ \\
\hline NADH oxidase (plasmalemma) & 0.489 & 0.011 & 2.3 & 15.1 & 0.041 & 8.4 & --- \\
\hline ATPase bafilomycin-A sensitive (tonoplast) & 1.79 & 0.28 & 15.16 & --- & 0.003 & 0.2 & 2.2 \\
\hline Cytochrome-c oxidase (mitochondria) & 10.01 & 0 & 0 & 0 & 0.026 & 0.25 & 3.0 \\
\hline $\begin{array}{l}\text { Antimycin A-insensitive cytochrome-c reductase } \\
\text { (endoplasmic reticulum) }\end{array}$ & 1.65 & 0.038 & 2.2 & 14.2 & 0.004 & 0.23 & 2.7 \\
\hline UDPase (Golgi) & 1.71 & 0.04 & 2.3 & 14.8 & 0.018 & 1.0 & 12.6 \\
\hline ATPase vanadate sensitive (plasmalemma) & 0.59 & 0.013 & 2.2 & 14.0 & 0.005 & 0.9 & --- \\
\hline
\end{tabular}

${ }^{\mathrm{z}}$ Microsomal pellet describes a membrane sample obtained by centrifuging the initial supernatant at $100,000 \mathrm{~g}$ for $1.5 \mathrm{~h}$. The sample contains all endomembrane systems, and activities of individual enzymes in this sample are considered as $100 \%$.

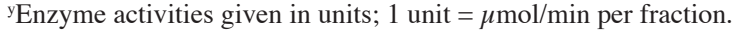

Table 2. Sidedness of tonoplast and plasmalemma fractions tested rapidly after isolation and after one cycle of freezing and thawing. Enzymes were assayed in the presence and absence of $10 \mu \mathrm{M} n$-dodecyl $\beta$-D-maltoside and expressed in $\mu \mathrm{mol} \cdot \mathrm{mg}^{-1}$ per minute prot. Percent sidedness was estimated using the activity in the presence of $n$-dodecyl $\beta$-D-maltoside as $100 \%$. Standard of error (SE) did not exceed $\pm 9 \%$. PPase was measured according to Marsh et al (2001).

\begin{tabular}{|c|c|c|c|c|c|c|c|c|}
\hline & \multicolumn{3}{|c|}{ Fresh } & \multirow{2}{*}{$\begin{array}{c}\text { Right side } \\
\text { out }(\%)\end{array}$} & \multicolumn{3}{|c|}{ Frozen/thawed } & \multirow{2}{*}{$\begin{array}{c}\text { Right side } \\
\text { out }(\%)\end{array}$} \\
\hline & - & n-dodecyl $\beta$-D-maltoside & + & & - & $n$-dodecyl ß-D-maltoside & + & \\
\hline$\overline{\text { NADH oxidase }}$ & 128.54 & & 178.53 & 72 & 92.89 & & 182.16 & 51 \\
\hline PPiase & 35.75 & & 41.82 & 82 & 34.63 & & 40.52 & 82 \\
\hline
\end{tabular}

10x with $10 \mathrm{~mm} \mathrm{BTP/Mes} \mathrm{(pH} \mathrm{7.5),} 20 \mathrm{~mm}$ $\mathrm{KCl}$ and $2 \mathrm{~mm} \mathrm{DTT}$ and centrifuged again for $60 \mathrm{~min}$ at $113,000 \mathrm{~g}$. Final re-suspension of the membrane pellet was done in $500 \mu \mathrm{L}$ of $10 \mathrm{~mm} \mathrm{BTP/Mes} \mathrm{(pH} \mathrm{7.5),} 2$ mм DTT and $250 \mathrm{~mm}$ sorbitol. This procedure resulted in a tonoplast fraction free of mitochondria and containing low levels of Golgi and ER contaminants (Table 1). The presence of plasmalemma marker activity in this fraction was unexpected, given the great difference in membrane densities. However, based on recent reports of rapid membrane vesicle trafficking from the plasmalemma to the vacuole, plasmalemma markers would be expected at the tonoplast of importing cells (Emans et al., 2002). Final recovery was $8.4 \%$ for plasmalemma and $15.6 \%$ for tonoplast, respectively.

Membrane sidedness was estimated for both plasmalemma and tonoplast using NADH oxidase and V-PPiase as markers, respectively. The enzymes were assayed in the presence and absence of $n$-dodecyl $\beta$-D-maltoside at a final concentration of $100 \mu \mathrm{M}$. Immediately after isolation, plasmalemma vesicles were $\approx 72 \%$ right side out; however, the orientation equilibrated to $\approx 50 \%$ after only one freeze/thaw cycle (Table 2). Our results are in accordance with those of Robbins et al. (1999) in which plasmalemma vesicles were predominantly right side out after isolation but randomized after freezing and thawing. Tonoplast vesicles were oriented $\approx 82 \%$ right side out after isolation, a property that remained unchanged after freezing and thawing (Table 2).

Given the differential capacity of each membrane system to turn inside out, it was then possible to determine whether different enzyme markers are simultaneously present in one population of hybrid vesicles, or whether the tonoplast fraction is made up of a mixed vesicle population. To find out the nature of the contamination within the tonoplast sample (plasmalemma was virtually free of tonoplast contamination), we measured changes in marker activities in freshly isolated membranes and after three freeze/thaw cycles. If the relative activity of the two markers enzymes remain the same after freeze and thawing, one would expect the two enzymes to be on the same vesicles. On the contrary, if NADH oxidase activity decreases relative to bafilomycin-A sensitive ATPase, one would conclude that two populations of membranes are present. As indicated in Table 3, NADH oxidase activity decreased $39 \%$ whereas bafilomycin-A sensitive ATPase declined $<6 \%$. From these data it is concluded that NADH oxidase and bafilomycin-A sensitive ATPase are not co-localized in hybrid vesicles but instead, they are present in separate membrane populations.

Since plasmalemma contamination within the tonoplast sample is present as a separate vesicle population, subjecting tonoplast samples to a two-phase partitioning treatment should reduce plasmalemma inclusion. After one wash through two-phase partitioning,
NADH oxidase activity in the tonoplast was further reduced by $25 \%$ (Table 4 ). The fact that the specific activity of bafilomycin-A sensitive ATPase increased after treatment corroborates the observation that both marker enzymes were localized in different populations. Therefore, considering an initial purity of $85 \%$ with respect to plasmalemma, a tonoplast sample subjected to an additional two-phase partitioning will be at least $90 \%$ free of plasmalemma. Production of mostly right-side out highly pure membranes is an invaluable tool in transport and receptor studies.

The method described in this communication produces highly pure tonoplast and plasmalemma fractions from Citrus juice cells competent for transport experiments. Based on the general similarities in membrane properties between plant species, this system is potentially valuable in membrane isolation of other agronomic plants.

Table 3. Activity of enzyme markers in tonoplast and plasmalemma preparations from sweet lime juice cells. Marker activities were assayed immediately after membrane isolation and after three cycles of freeze/ thaw in three different preparations. Experiments were conducted in triplicates from three separate membrane samples. Standard of error (SE) did not exceed $\pm 6 \%$.

\begin{tabular}{lccc}
\hline & \multicolumn{2}{c}{ Activity } & \\
& $(\mu \mathrm{mol} / \mathrm{min}$ per fraction $)$ & \\
\cline { 2 - 3 } & Fresh & Frozen/thawed & Change (\%) \\
\hline ATPase bafilomycin sensitive & 0.294 & 0.277 & -5.8 \\
NADH oxidase & 0.017 & 0.011 & -38.8 \\
\hline
\end{tabular}

Table 4. Activity of tonoplast and plasmalemma marker enzymes in tonoplast preparations before and after two-phase partitioning. Specific activity given in $\mu \mathrm{mol} \cdot \mathrm{mg}^{-1}$ per minute prot. and total activity in $\mu \mathrm{mol} \cdot \mathrm{mg}^{-1}$ per fraction. Experiments were conducted in triplicates from three separate membrane samples. Standard of error (SE) did not exceed $\pm 8 \%$.

\begin{tabular}{lcccccc}
\hline & \multicolumn{2}{c}{$\begin{array}{c}\text { Tonoplast sample after } \\
\text { sucrose density gradient }\end{array}$} & & & \multicolumn{2}{c}{$\begin{array}{c}\text { Tonoplast sample after } \\
\text { 2-phase partitioning }\end{array}$} \\
\cline { 2 - 3 } \cline { 5 - 6 } & Specific activity & Total activity & & Specific activity & Total activity \\
\hline ATPase bafilomycin sensitive & 0.344 & 69.25 & & 0.403 & 19.83 \\
NADH oxidase & 0.503 & 101.25 & & 0.273 & 18.35 \\
\hline
\end{tabular}




\section{Literature Cited}

Barkla, B. and O. Pantoja. 1996. Physiology of ion transport across the tonoplast of higher plants. Ann. Rev. Plant Physiol. Mol. Biol. 47: 159-184.

Brune, A., M.L. Müller, L. Taiz., P.C. Gonzalez, and E. Etxeberria. 2002. Vacuolar acidification in citrus fruits: Comparison between acid lime (Citrus aurantifolia) and sweet lime (Citrus limmetioides) juice cells. J. Amer. Soc. Hort. Sci. 127:171-177.

Echeverria, E., A. Brune, and P.C. Gonzalez. 1997. Characterization of proton and sugar transport at the tonoplast of sweet lime (Citrus limmetioides) juice cells. Physiol Plant 101:291-300.

Emans, N., S. Zimmermann, and R. Fischer. 2002. Uptake of a fluorescent marker in plant cells is sensitive to brefeldin A and wortmanin. Plant Cell 14:71-86.

Getz, H.P. 1991. Sucrose transport in tonoplast vesicles of red beet roots is linked to ATP hydrolysis. Planta 185:261-268.

Hadzi-Taskovic, V. and M. Vuletic. 1998. Properties of peroxidase activities in plasma membrane and cell wall from maize root. Iguoslav. Physiol. Pharmacol Acta. 35:1103-109.
Joyce, C.D., R.G. Cramer, M.S. Reid, A.B. Bennett. 1988. Transport properties of the tomato fruit tonoplast. Plant Physiol. 88:1097-1103.

Keller,F. 1992. Transport of stachyose and sucrose by vacuoles of Japanese artichoke (Stachys sieboldii) tubers. Plant Physiol. 98:442-445.

Larsson, C., S. Widell, and P. Kjellbom. 1987. Preparation of high-purity plasmalemma membranes. Methods Enzymol. 148:558-567.

Maathuis, F.J.M. and D. Sanders. 1999. Plasma membrane transport in context-Making sense out of complexity. Curr. Opin. Plant Biol. 2: 236-243.

Marsh, K., P. Gonzalez, and E. Echeverria. 2001. Partial characterization of $\mathrm{H}+$-translocating inorganic pyrophosphatase from 3 citrus varieties differing in vacuolar $\mathrm{pH}$. Physiol. Plant. 111:519-526.

Martinoia, E., A. Massonneau, and N. Frangne. 2000. Transport processes of solutes across the vacuolar membrane of higher plants. Plant Cell Physiol. 41:1175-1186.

Milner, I.D., L.C. Ho, and J.L. Hall. 1995. Properties of proton and sugar transport at the tonoplast of tomato (Lycopersicum esculentum) fruit. Physiol Plant 94:399-410.

Müller, M.L., U. Irkens-Kiesecker, D. Kramer, and
L. Taiz. 1997. Purification and reconstruction of the vacuolar $\mathrm{H}^{+}$-ATPases from lemon fruits and epicotyls. J. Biol. Chem. 272:12762-12770.

Müller, M.L., U. Irkens-Kiesecker, B. Rubinstein, and L. Taiz. 1996. On the mechanism of hyperacidification in lemon. Comparison of the vacuolar $\mathrm{H}^{+}$-ATPase of fruits and epicotyls. J. Biol. Chem. 271:1916-1924.

Patrick, J.W. 1997. Phloem unloading: Sieve element unloading and post-sieve element transport. Ann. Rev. Plant. Physiol. Mol. Biol. 48:191-222.

Presser, J. and E. Komor. 1991. Sucrose uptake into the vacuole of sugarcane suspension cells. Planta 186:109-114.

Robbins, K.M., N. Bhuvarahamurthy, G. Pliska-Matyshak, and P.N. Murthy. 1999. The isolation and characterization of right-side-out plasma membrane vesicles from barley aleurone cells. Lipids 34:7582.

Ruan, Y-L., J. Patrick, and C. Brady. 1997. Protoplast hexose carrier activity is a determinate of genotypic difference in hexose storage in tomato fruit. Plant Cell Environ. 20:341-349.

Yamaki, S. 1987. ATP-promoted sorbitol transport into vacuoles isolated from apple fruit. Plant Cell Physiol. 28:557-564. 